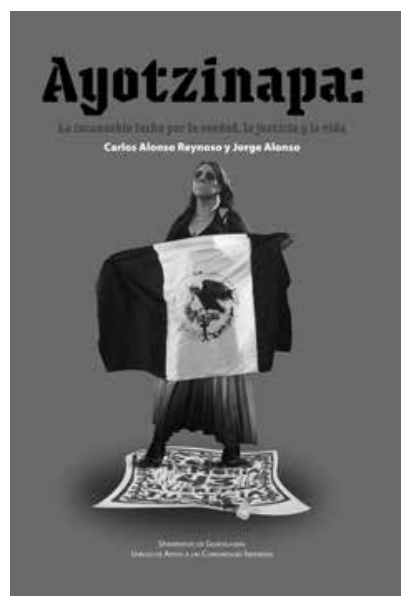

Seeking the Truth to Achieve Social Justice

ZULAY C. DIAZ MONTIEL Universidad del Zulia, Maracaibo, Venezuela diazzulay@gmail.com

Desacatos 56 , enero-abril 2018, pp. 194-196
- Ayotzinapa: la incansable lucha por la verdad, la justicia y la vida CARlos Alonso ReYnoso

Y JORGE ALONSO, 2016

Universidad de Guadalajara, México

\section{Buscar la verdad para lograr justicia social}

\author{
ZULAY C. DÍAZ MONTIEL
}

aUniversidadde Guadalajara, desdela VicerrectoríaEjecutiva, por medio de la Coordinación de Vinculación y Servicio Social y la Unidad de Apoyo a las Comunidades Indígenas, publicó un importante libro, Ayotzinapa: la incansable lucha por la verdad, la justicia y la vida, de Carlos Alonso Reynoso y Jorge Alonso. En este proyecto editorial, realizado con verdadera excelencia investigativa, bajo un estricto proceso de evaluación académica, los autores reflexionan acerca de la novedosa praxis sociopolítica emancipadora que sirve de origen y causa al Movimiento Ayotzinapa, como una práctica disidente para la organización política de los de abajo. ${ }^{1}$

1 Los autores señalan que desde 2011 han aparecido en el espacio público de varios países movimientos sociales con nuevas características en su actuación política, como el M15 o "movimiento de los indignados" en España, la Primavera Árabe, Occupy Wall Street en Estados Unidos y las manifestaciones contra la austeridad en Grecia, entre otros. Estos movimientos sociales, al igual que el Movimiento Ayotzinapa desde 2014 en México, crean una nueva forma de irrumpir en el espacio público y buscan nuevas formas de hacer política (p. 9). 
La publicación del libro obedece a los lamentables hechos acaecidos en la ciudad de Iguala, México, el 26 de septiembre de 2014, en los que "murieron seis personas, tres de ellos normalistas, hubo dos decenas de heridos y 43 estudiantes normalistas sufrieron desaparición forzosa" (p. 14). En medio de esta tragedia, para los autores es de sumo interés lo novedoso que ha sido para México y el mundo el tránsito del Movimiento Ayotzinapa durante dos años, en su búsqueda por la verdad y la justicia social. En este tiempo aciago para las víctimas, se ha podido mostrar la estructura de un Estado criminal que responde con impunidad a las demandas de justicia. Se observa que esto se ha convertido en su modus operandi, encubridor de crímenes de lesa humanidad.

Aunado a esto, Alonso Reynoso y Alonso, de manera incisiva y puntual, observan en el Movimiento Ayotzinapa una praxis intersubjetiva, dialógica y ética, que expresa y reitera el sentido de emancipación que portan sus luchas en tanto correlato existencial de su quehacer cotidiano. También en el desarrollo de la resistencia cívica y política este movimiento social ha superado censuras, represiones e inhibiciones de los organismos gubernamentales mexicanos, gracias a la defensoría de organismos internacionales, con marcada creatividad y exigencia moral, para solicitar justicia de un Estado indolente que irrespeta la condición y dignidad humana.

Los autores expresan que desde 2014 hasta nuestros días el Movimiento Ayotzinapa ha impregnado sus denuncias con un discurso crítico y se ha comprometido con el desafío que implica la construcción solidaria de nuevas realidades sociopolíticas, que comienzan a trazar posibles caminos con un sentido social más auténtico. El movimiento es un testimonio viviente de la emergencia de actores invisibilizados a lo largo de la historia bajo el peso hegemónico de los Estados neoliberales en Latinoamérica.

En su afán por desvelar cómo por medio del Movimiento Ayotzinapa se expresan nuevas formas de pensar y actuar, ${ }^{2}$ Alonso Reynoso y Alonso observan una periodicidad intensiva en su modo de proceder, jamás vista en otros movimientos sociales. Al mismo tiempo que siguen el rastro de esa actuación, se reproducen nuevas acciones creadoras de la solidaridad necesaria para que sus luchas se identifiquen con las luchas de todos: se abren espacios políticos alternativos de convergencia plural.

Desde el principio, la solidaridad con otros que también soportan — muchas veces en silencio- la indiferencia de organismos gubernamentales cuando de imponer justicia se trata, la violencia de la exclusión, la inhumanidad de la pobreza y la incansable lucha por la vida ha sido la motivación para tomar las calles, lo que ha hecho posible sacar a la luz pública el sistema de corruptela, impunidad, violencia y muerte de tantos desaparecidos.

La obra comienza con una "Introducción" que contextualiza los cambios que están ocurriendo en el mundo en la forma de hacer política desde abajo. Siguen cuatro capítulos, cada uno con sus consideraciones finales, que dejan la puerta abierta para seguir reflexionando.

En el capítulo I, "Una visión sintética de la irrupción del movimiento y de su inicial accionar", se describen de forma asertiva y contundente los hechos que dieron origen al Movimiento Ayotzinapa. Con gran especificidad, los autores ponen a la vista del lector la trama de engaños y arbitrariedades de las versiones gubernamentales acerca de los hechos. Asimismo, se dan a conocer las actuaciones de los organismos defensores de los derechos humanos -Human Rights Watch, Amnistía Internacional,

"El movimiento de Ayotzinapa ha tenido una intensidad que no se le había visto a otros movimientos de este tipo [...]. Queremos comprender lo que lo hace específico. Ha conmovido profundamente a México y al mundo. Tiene un objetivo vital que lo hace existir y ser y un componente de [...] oportunidad para la convergencia de muchas luchas" (p. 10). 
Oficina Latinoamericana en Washington, Centro de Derechos Humanos de la Montaña de Guerrero Tlachinollan- y de la Iglesia católica. A partir de esto, se explica cómo empezó un movimiento plural y diverso por la vida, que agrupa y moviliza a varios movimientos sociales para hacer un frente unificado para la protesta social que criminaliza la acción del Estado mexicano.

En el capítulo II, "La centralidad del grupo de expertos independientes de la CIDH y la marcha del proceso hasta finales de 2015", de nuevo se revela la ineptitud en el diligenciamiento de la verdad por parte de la Procuraduría General de la República (PGR). Los entrampamientos gubernamentales, en los que se trata de enlodar la imagen de algunos de los normalistas desaparecidos, y la corrupción y la desidia que campean, según describen los autores, se convierten en fuerzas motivadoras para juntar los dolores que hacen crecer la solidaridad y florecer los caminos que la reproducen. El desenmascaramiento de la mentira se exige desde la fuerza que el apoyo de los grupos aporta. Zapatistas, intelectuales de la Feria Internacional del Libro de Guadalajara, miembros del Congreso Nacional Indígena, el Centro de Derechos Humanos y la voz internacional, entre otras no menos importantes, se convierten en un aliciente para la lucha humanitaria.

En el capítulo III, "La estrategia estatal contra el GIEI [Grupo Interdisciplinario de Expertas y Expertos Independientes] y el movimiento de Ayotzinapa", Alonso Reynoso y Alonso insisten en denunciar que el Estado arremete vilmente contra el Movimiento Ayotzinapa y los grupos aliados, hasta el punto de degradar la política mexicana a una guerra que el capitalismo ha emprendido contra los de abajo. Se explica cómo el Movimiento construye un nuevo modo de actuación política para resistir los ataques de los de arriba.
En el capítulo IV, "Diversos énfasis en torno al Movimiento de Ayotzinapa", se interpreta el impacto nacional e internacional que causó en internet el Movimiento en el primer semestre de 2016. Se realiza un análisis exhaustivo de las publicaciones tanto académicas como de opinión, y se aplica con mucha responsabilidad la perspectiva multiversa de presentación del problema estructural de violencia del Estado mexicano, así como lo que significa el Movimiento Ayotzinapa desde una reflexión política profunda, que incide en el repudio nacional e internacional que se hace expreso con mucha firmeza y solidaridad.

Una bibliografía vasta y la revisión de información en la web respaldan este trabajo de investigación para ser presentado a las redes latinoamericanas interesadas en el estudio de las ciencias sociales y la crisis de los sistemas políticos, la discusión teóricopráctica respectiva, y a la opinión pública en general. El Movimiento Ayotzinapa, más que como un movimiento social, se constituye en vanguardia de los de abajo, que buscan emanciparse de la opresión de los de arriba, y lleva como estandarte la construcción de un nuevo mundo.

En la lectura del libro se percibe la originalidad de la obra. Desde el punto de vista personal, la experiencia lograda con esta lectura me lleva a entender el Movimiento Ayotzinapa como un registro de las transformaciones sociales comunitarias surgidas de una praxis política solidaria y pública, de una vocación democrática manifiesta en la sociedad latinoamericana en general y expresada en la autonomía de ciudadanos que asumen su responsabilidad moral para hacer un mundo mejor para todos los involucrados: "un movimiento como el de Ayotzinapa [sigue] siendo necesario" (p. 210). 